\title{
Influence of Children's Health On Primary School Academic Performance In Africa. A Case Study of Fort Portal Municipality, Kabarole District, Uganda.
}

\author{
Brenda Kanyesige ${ }^{a}$ \\ ${ }^{a}$ Faculty of Social Sciences, Makerere University
}

\begin{abstract}
\end{abstract}

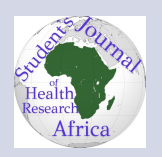

Background:

The world population comprises 2.2 billion children below 18 years, 1.9 billion of which live in developing countries, 1 billion being caught up below the poverty line, and 340 million in sub-Saharan Africa. 640 million do not have adequate shelter, 400 million do not have safe drinking water and 270 million have no access to health services. In Uganda, better health care is widely thought to improve primary school performance and post-school productivity. This study investigated the influence of children's health on primary school academic performance in Fort Portal municipality, Kabarole district.

Methodology:

Questionnaires were used as the major research tool and it was supplemented through the use of interview guide and Focus Group Discussion guide. Data collection was then followed by analysis and interpretation of findings.

\section{Results:}

$49.5 \%$ of children fall sick at least once a year. $20.6 \%$ fall sick once every two months, $15.5 \%$ monthly, $8.2 \%$ twice a week and $6.2 \%$ once a week. The major effects of poor health on academic performance include; absenteeism, lack of concentration in class, missing tests and exams. Girls get preferential treatment when it comes to accessing medical care from the school nurse. The study showed that provision of medicine was viewed as the best option.

\section{Conclusion}

Malaria, cough and flu are the most common health problem faced by pupils and poor health affects children's academic performance.

\section{Recommendations: ${ }^{a}$}

Massive sensitization campaign about the spread of cough and flu, enhancing health education in schools, recruitment of nurses that would be residents in schools, economic empowerment of parents, encouraging more NGOs to extent their work in health services to Fort Portal Municipality and provision free health services to school going children as well as regular medical check up preferably once every three weeks.

\footnotetext{
${ }^{a}$ email:brendakanye@gmail.com submitted: 26th/08/2021 accepted: 10th/09/2021
}

\section{Background to the study}

The world population comprises 2.2 billion children below 18 years, 1.9 billion of which live in devel- oping countries, 1 billion being caught up below the poverty line, and 340 million in sub-Saharan Africa. 640 million do not have adequate shelter, 
400 million do not have safe drinking water and 270 million have no access to health services (UNICEF, 2005).

The situation is worse in Africa and Asia where over $60 \%$ of the population barely meets their minimum caloric requirement necessary to maintain adequate health (Todaro et al., 2003). The majority of these are children of primary school-going age. It is imperative to note that they have been damaged psychologically worsening their school performance. Thus, this study seeks to find out those factors' implications of poor health on school performance.

According to $\mathrm{MOH}$ (April, 2003), approximately 67 percent of Ugandan children do not have access to proper medical. This makes them susceptible to long illness which may culminate into death. A report from UNICEF (2005) also revealed more than $60 \%$ of children in war-torn areas like Northern Uganda do not attend school regularly due to ill health. The above statistics show that health care and education has become increasingly information-intensive from all perspective, from the health and educational professional to the general public, one vital aspect of a nation's health and wealth has been under looked, that is children's health and their school performance.

Education and health care have been identified as basic objectives of development and are considered as important ends in themselves, and the government of Uganda and the international donor community have committed big sums of money and resources towards the health and education of its children. However, there are still many cases of days lost from school due to the poor health of primary school children which is reflected in their performance (Behrman et al., (1994). Based on the above, the study sought to find out the cause of the prevalence of poor health and what needs to be done to improve the quality of education in Uganda.

In Uganda, better health care is widely thought to improve primary school performance and postschool productivity. Improved child health and nutrition is, therefore, welfare-enhancing. Children's health and educational performance is believed to reflect household decisions regarding investment in children's human capital (Todaro et al., 2003). It is the contention of this study to examine the extent to which children's health has a bearing on primary school performance. Much as the Government of
Uganda (GOU) has spent a substantial amount of resources in improving educational attainment and quality over the years, the indicators of education are still poor when compared to those of other countries of SSA.

Uganda's education system has been characterized by wastage of resources in form of repeating classes or grades due to poor performance, high rate of dropouts leading to low completion of primary education. Unfortunately, over the years, many reasons like family status, poverty children's and parents' attitudes towards education, distance to school, and many others have been advanced, ignoring one vital factor children's health.

Similarly, the GOU introduced the Universal Primary Education (UPE) policy in 1997 to solve the educational challenges in Uganda. This led to a tremendous increase in primary school enrolment from 2,100,000 in 1997 to $6,800,000$ in 2004. Still, the critique of the UPE policy argues that on the contrary, it is promoting a sub-standard education with the policy of automatic promotion, overcrowding in classrooms, and forcing pupils to study under trees in many districts. This compounded by the fact that inadequate health facilities worsens the sanitation of schools and has a direct impact on the health of school-going children, but has never been addressed calls for a study to examine how this impacts their performance.

Besides the UPE policy to improve educational quality and attainment for an average Ugandan pupil, the GOU and Civil Society Organizations (CSOs) have been trying to identify such factors which affect the quality of education, and among the measures to improve educational performance service teachers development programs, improving pupil: textbook ratio to ensure accessibility, increasing community sensitization and awareness, forgetting one vital factor children's health.

Gender sensitization concerns have also risen over the years in a bid to protect the girl child who is finding increasing difficulties to access education since a large majority of them have irregular school attendance being reflected in their school performance. Much legislation has been made in line with children's education like the UNICEF, African Union (AU), and GOU: 1995, and many others. However, despite all these struggles to improve the performance of a primary school, the majority still perform poorly. Even with the introduction of decentralization and sensitization, school-based infor- 
mation reveals that the percentage of those who perform fairly still needs to be examined children's health being one among others

Health and adequate nutrition are pillars of learning throughout life (Bellamy, 1999). Although health in one way or the other has been identified as a factor that affects primary school performance, it has just been looked at in general. Children of developing countries are caught up in a constant struggle against respiratory illness, diarrhea, malaria, helminthes, iodine, deficiencies, malnutrition, visual problems, and many others (UNICEF, 1999).

According to the constitution of Uganda, 1995, the state has to provide adequate health care to children. The target of the government is to increase immunization from $31 \%$ to $62 \%$ and provision of safe drinking water to $100 \%$ by 2017 . However, presently the government cannot provide these health care requirements and as such it's the parents and caregivers who are in this constant struggle to provide the necessary health care needed by the children. It is therefore important to examine their health situation and how it impacts their academic performance.

Ugandan education is viewed as one policy among others for the country's development. To promote education in the country, the government introduced (UPE) in 1997 and later Universal Secondary Education (USE) in 2007. Much emphasis is put on the promotion of science subjects and academic excellence at all levels. However, the implication of children's health as a possible cause of poor performance has not been fully examined. Uganda's school-going children suffer from diseases like HIV/AIDS, dysmenorrheal, cough, and common cold which in most cases do not reach doctors as a result of the high level of poverty in the country which implies that many parents cannot afford medical care for their children. The situation is further worsened by the fact that there are disparities in the access to medical care between girls and boys. Unfortunately, boys are normally favored in the provision of medical care.

\section{METHODOLOGY Research design}

The study used a descriptive research design. It mainly describes the influence of children's health on performance. It was carried out in the South and Eastern zones in Fort Portal Municipality.

\section{Sampling techniques}

Purposive sampling was used to select pupils who were included in the study. The study included 3 schools that were randomly selected in the region.

\section{Sample size}

The overall sample of the respondents was 109 which included 97 children, 9 parents, and 3 teachers from 3 different schools in Kabarole district.

\section{Instruments}

The study employed three research instruments to collect data from the respondents.

\section{Questionnaires}

Self-administered questions in English language were distributed to the respondents in each school. The questionnaires were used to get information from the 3 teachers, 9 parents, and 97 pupils in their respective schools; the reason for this is that it is an easy way of reaching all these respondents since they were not located in the same school.

\section{Interview guide}

This will be used specifically to gather information from head teachers. The interviews were conducted with the help of interview guides which consisted of questions related to the research objectives.

\section{Focus Group Discussion (FGD) guide}

This was composed of 9 parents selected using convenience sampling. The FGD was guided by a moderator appointed by the group members themselves. The FGD was conducted for one hour and a question and answer approach was used. The purpose of this group discussion was to bring out different views from parents about what common health problems are affecting their children.

\section{Validity and reliability of instruments}

The supervisor cross-checked the instruments and made the necessary comments and to improve the validity and reliability of the instruments. All this was done to check for possible errors and omissions in the instruments and to make adjustments that helped to perfect and ensure validity and reliability of the instruments in meeting the purpose of the investigation.

\section{Ethics considerations:}

A formal Ethics clearance letter was obtained from the faculty of social sciences, Makerere University, which together with the introduction letter 
was provided to the selected school administrators where the study was conducted.

Informed written consent was provided by teachers and parents before data was collected from them. Only Children who showed interest, and whose biological parents and guardians provided written informed consent on their behalf were included in the study. Data collected was kept under lock and key, only accessed by the authorized research team.

\section{Data collection procedure:}

The selected schools were visited twice; 1 ). When issuing the questionnaires, and 2 ). When collecting the completed ones. This was done within a period of one week. Face-to-face interviews with the head teachers were conducted in the second visit. After the collection of the data, it was analysed while ensuring that the study remained focused on meeting its objectives and purpose. A presentation of the study findings was then done by writing the report which was typed, proofread, bound, and handed to the supervisor for signing. Thereafter, the final report was submitted to the Faculty of Social Sciences, and the schools that took part in the study.

\section{Data analysis}

Data were coded by classifying answers to each of the questions into meaningful categories to bring out their essential pattern. In this particular case, both closed and open-ended questions were coded so that data entry was done using Statistical Package for Social Scientists (SPSS). Presentation of the research findings was then done using frequencies and percentages. Thematic analysis of the information generated using interviews and Focus Group Discussion was also undertaken.

\section{Results and analysis of the study findings.}

This section includes only data for 97 respondents.

\section{distribution of respondents by age} ( $\mathrm{n}=97$ )

The study also investigated the sex composition of the respondents and the results are presented in Table 2.

\section{$(\mathrm{n}=97)$}

The study sought to establish the class distribution of respondents and the results are presented in Table 3.

$(n=97)$
Data was collected on the distribution of the respondents by religion and the study findings are as presented in Table 4.4.

\section{$(\mathrm{n}=97)$}

The study sought to establish the distribution of respondents by the occupation of their parents and the results are presented in Table 5.

\section{$(\mathrm{n}=97)$}

Common health problems that affect primary school performance in Fort-Portal municipality, Kabarole district

The study sought to establish the common health problems that affect primary school performance in Fort-Portal Municipality, Kabarole district. Figure 1 presents findings on how often children fall sick using frequency.

Figure 1: Frequency of occurrence of sickness among children $(n=97)$

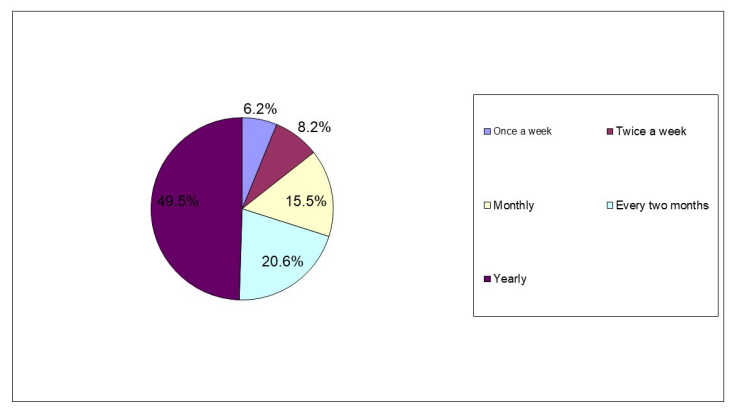

The respondents were also asked what kind of sick they always suffer from and the results are presented in Figure 2 below;

$(n=97)$

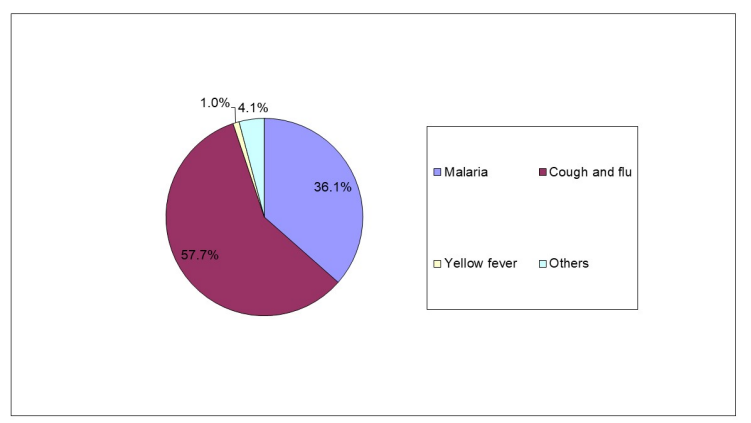

The pupils were further asked whether their friends always fall sick as their responses are presented in Table 6.

( $\mathrm{n}=97$ )

The pupils were further asked the kind of sickness that their friends usually suffer from and the findings are presented in Table 7. 
Table 1. distribution of respondents by age

\begin{tabular}{lll}
\hline Age group & Frequency & Percentage \\
$10-14$ & 90 & 92.8 \\
$15-19$ & 7 & 7.2 \\
Total & $\mathbf{9 7}$ & $\mathbf{1 0 0}$ \\
\hline
\end{tabular}

Table 2. Distribution of respondents by sex

\begin{tabular}{lll}
\hline Sex & Frequency & Percentage \\
Male & 51 & 52.6 \\
Female & 46 & 47.4 \\
Total & $\mathbf{9 7}$ & $\mathbf{1 0 0}$ \\
\hline
\end{tabular}

Table 3. Distribution of respondents by class

\begin{tabular}{lll}
\hline Class & Frequency & Percentage \\
Primary five & 37 & 38.1 \\
Primary six & 28 & 28.9 \\
Primary seven & 32 & 33.0 \\
Total & $\mathbf{9 7}$ & $\mathbf{1 0 0}$ \\
\hline
\end{tabular}

Table 4. Distribution of respondents by religion

\begin{tabular}{lll}
\hline Religion & Frequency & Percentage \\
Catholic & 29 & 29.9 \\
Protestant & 54 & 55.7 \\
SDA & 3 & 3.1 \\
Islam & 11 & 11.3 \\
Total & $\mathbf{9 7}$ & $\mathbf{1 0 0}$ \\
\hline
\end{tabular}

Table 5. Distribution of respondents by the occupation of their parents

\begin{tabular}{lll}
\hline Occupation of parents & Frequency & Percentage \\
Civil servant & 30 & 30.9 \\
NGO workers & 19 & 19.6 \\
Business Man/Woman & 37 & 38.1 \\
Peasant farmer & 11 & 11.3 \\
Total & $\mathbf{9 7}$ & $\mathbf{1 0 0}$ \\
\hline
\end{tabular}

Table 6. Whether their friends always fall sick

\begin{tabular}{lll}
\hline Response & Frequency & Percentage \\
Yes & 75 & 77.3 \\
No & 22 & 22.6 \\
Total & 97 & 100 \\
\hline
\end{tabular}




\section{$(n=75)$}

Data was also collected on whether there has been a general outbreak of particular disease in the schools and the responses of the pupils are presented in Table 8.

$(n=97)$

Figure 3: Kind of disease outbreak in the school

$(n=23)$



How poor health affect children's academic performance in Fort portal Municipality Kabarole district

This section presents findings on how poor health affects children's academic performance in Fort portal Municipality Kabarole district. The respondents were asked about their class position in the previous term (Term II). However, the respondents answered using grades which are displayed in Figure 4.

Figure 4: Class grade of respondents

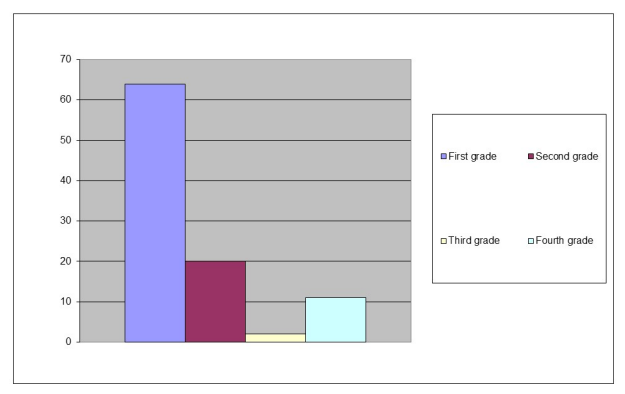

The respondents were further asked they thought that sickness had affected their academic performance and the results are presented in Table 9.

\section{$(n=97)$}

The respondents were asked to specify the effect of sickness on their performance and the results are presented in Figure 5.
Figure 5: Effect of sickness on the performance of pupils

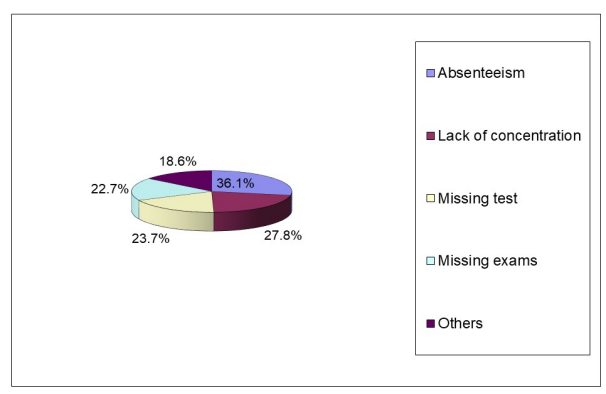

Pupils were further asked whether they had friends who had failed exams due to sickness and the results are presented in Table 10.

\section{$(\mathrm{n}=97)$}

The respondents were asked about the reasons for missing school and the results are as presented in Table 11.

\section{( $\mathrm{n}=97$ )}

The study further sought to establish the number of times students miss school and the results are as presented in Figure 6.

Figure 6: Frequency of missing school



\section{Gender disparities in health care provision among boys and girls of school going age}

The respondents were asked whether they have a senior woman teacher who guides them on issues of reproductive health and the results are presented in Table 12.

\section{$(\mathrm{n}=97)$}

The respondents were further asked how often the senior woman teacher interacts with the female pupils and the findings are as presented in Table 13.

\section{$(n=46)$}

Findings in Table13 show that nearly half of the children (45.7\%) pointed out that the senior woman 
Table 7. Kind of sickness that affects their friends

\begin{tabular}{lll}
\hline Kind of sickness & Frequency & Percentage \\
Malaria & 33 & 44.0 \\
Cough and flu & 41 & 54.7 \\
Others & 1 & 1.0 \\
Total & $\mathbf{7 5}$ & $\mathbf{1 0 0}$ \\
\hline
\end{tabular}

Table 8. Case of particular disease outbreak in the school

\begin{tabular}{lll}
\hline Response & Frequency & Percentage \\
Yes & 23 & 23.7 \\
No & 74 & 76.3 \\
Total & $\mathbf{9 7}$ & $\mathbf{1 0 0}$ \\
\hline
\end{tabular}

Table 9. Whether sickness affected their performance

\begin{tabular}{lll}
\hline Response & Frequency & Percentage \\
Yes & 58 & 59.8 \\
No & 39 & 40.2 \\
Total & 97 & 100 \\
\hline
\end{tabular}

Table 10. Whether children ever miss school

\begin{tabular}{lll}
\hline Response & Frequency & Percentage \\
Yes & 73 & 75.3 \\
No & 24 & 24.7 \\
Total & 97 & 100 \\
\hline
\end{tabular}

Table 11. Reasons for missing school

\begin{tabular}{lll}
\hline Reason & Frequency & Percentage \\
Fever & 33 & 34.0 \\
Menstruation & 14 & 14.4 \\
Household chores & 7 & 7.2 \\
School fees & 23 & 23.7 \\
Others & 4 & 4.1 \\
\hline
\end{tabular}

Table 12. Existence of a senior woman teacher

\begin{tabular}{lll}
\hline Response & Frequency & Percentage \\
Yes & 96 & 99.0 \\
No & 1 & 1.0 \\
Total & $\mathbf{9 7}$ & $\mathbf{1 0 0}$ \\
\hline
\end{tabular}


Table 13. Attendance to children by the senior woman teacher

\begin{tabular}{lll}
\hline Response & Frequency & Percentage \\
Once a term & 15 & 32.6 \\
Twice a term & 21 & 45.7 \\
Three times a term & 10 & 21.7 \\
Total & $\mathbf{4 6}$ & $\mathbf{1 0 0}$ \\
\hline
\end{tabular}

teacher attends to girls twice in a term. Data was also collected on whether the respondents receive health services at school and the results are displayed in Table 20.

\section{$(n=97)$}

Findings in Table 15 show the responses of the pupils when they were asked whether they have a school nurse.

\section{$(n=97)$}

Table 15 shows that more than have of the respondents answered that they had a school nurse who treats children in case they are sick. This was also confirmed through interviews with the head teachers of the selected schools. The respondents were further asked the number of days in a week they are attended to by the school nurse and the findings are presented in Table 16.

\section{$(n=97)$}

The respondents were asked whether boys and girls receive equal treatment in accessing medical care and the findings are as displayed in Table 17.

\section{$(n=97)$}

Table 17 shows that boys and girls get equal treatment in accessing health care. This is because majority of the respondents answered yes when they were asked whether boys and girls get equal treatment. The study further sought to establish who gets preferential treatment in accessing medical care between boys and girls and the results are as displayed in Figure 7.

Figure 7: Who gets preferential treatment in getting medical care

$(n=97)$



Findings in Figure 7 illustrate that girls get preferential treatment when it comes to accessing medical acre from the school nurse. One of the head teachers noted that some boys usually complain that the school only treats girls, but this is not true since the school adequately takes care of sick children regardless of their sex.

Strategies to address the specific health care needs of children for purposes of improving their academic performance

This section deals with findings on the strategies to address the specific health care needs of children for purposes of improving their academic performance. Data was collected on the strategies being used by the school to help children who fall sick at school and the results are presented in Table 18.

\section{$(n=97)$}

Data was collected on the strategies being used by the schools to prevent children from falling sick and the result are presented in Table 4.19.

$(n=97)$

This section includes responses from the selected teachers and Parents

Through Focus Group Discussion most parents disagreed with the issues disparities in accessing health services between boys and girls at home. They said that this is not common in an urban setting because people are literates and they are often sensitized in radios to value the girl child and cater for all children equally. 
Table 14. Whether children receive health services

\begin{tabular}{lll}
\hline Response & Frequency & Percentage \\
Yes & 95 & 97.9 \\
No & 2 & 2.1 \\
Total & 97 & 100 \\
\hline
\end{tabular}

Table 15. Existence of a school nurse

\begin{tabular}{lll}
\hline Response & Frequency & Percentage \\
Yes & 57 & 58.8 \\
No & 40 & 41.2 \\
Total & $\mathbf{9 7}$ & $\mathbf{1 0 0}$ \\
\hline
\end{tabular}

Table 16. Attendance to children by the school nurse

\begin{tabular}{lll}
\hline Response & Frequency & Percentage \\
Daily & 94 & 96.9 \\
Weekly & 3 & 30.9 \\
Total & $\mathbf{9 7}$ & $\mathbf{1 0 0}$ \\
\hline
\end{tabular}

Table 17. Whether boys and girls get equal treatment in accessing health care

\begin{tabular}{lll}
\hline Response & Frequency & Percentage \\
Yes & 86 & 88.7 \\
No & 11 & 11.3 \\
Total & $\mathbf{9 7}$ & $\mathbf{1 0 0}$ \\
\hline
\end{tabular}

Table 18. Strategies used by schools to help children who fall sick

\begin{tabular}{lll}
\hline Strategies & Frequency & Percentage \\
Provide medicine & 97 & 100 \\
Taken to hospital & 75 & 77.3 \\
Attended to by school nurse & 77 & 79.4 \\
Given special food & 14 & 14.4 \\
Others & 8 & 8.2 \\
\hline
\end{tabular}

Table 19. Strategies used by schools to prevent children from falling sick

\begin{tabular}{lll}
\hline Strategies & Frequency & Percentage \\
Advised to clean compound & 95 & 97.9 \\
Personal hygiene & 91 & 93.8 \\
Advised to sleep under mosquito net & 81 & 83.5 \\
\hline
\end{tabular}




\section{Gender disparities in health care provision among boys and girls of school going age}

Through Focus Group Discussion with the parents, they noted that illness retards performance of children. They pointed out that sickly cannot concentrate in class when a teacher is teaching always sleeping on the desk thus leading to poor performance at the end of term.

Poor health leads to absenteeism as was pointed out by one of the parents "you know these schools in town when a child misses school for only one day you find that he/she missed a lot in class, unlike rural schools". Parents argue that illness leads to mental incapacities and sick children cannot venture beyond the teachers work since teachers give only $30 \%$ a sickly child can hardly revise extensively thus affecting their performance.

The parents also noted that sickly children are always isolated from their friends both at home and at school which influences their performances. The fact that not all children can learn from their teachers in class, but when they associate with friends and discuss what they have learnt which excludes sickly children who are isolated and never there with their friends.

Results in Table 12 shows that more than three quarters of the children (99.0\%) pointed out that they had a school nurse. Findings through interview with the head teachers also showed that all the schools had a school nurse.

Findings in Table13 showed that nearly half of the children (45.7\%) pointed out that the senior woman teacher attends to girls twice in a term.

hows that children receive health services at the school. This was supported by the head teachers who were interviewed about the existence of health services in their schools.

How poor health affect children's academic performance in Fort portal Municipality Kabarole district

Figure 4 shows that majority of the respondents were performing quite well. This is reflected in the fact 64 children had scored first grade in the second term exams. The results also show that although majority of the pupils were performing well, nearly a quarter of the children (11 children) were performing quite poorly and they scored fourth grade.

Findings in Table 9 shows that the performance of majority of the pupils (59.8\%) had been affected by sickness. This means that the academic per- formance of the children would have been much better if it had not been compromised by sickness.

Results in Figure 5 shows that the major effect of sick on the performance of students was absenteeism (36.1\%). This was then followed by lack of concentration in class $(27.8 \%)$, missing tests (23.7) and exams (22.7\%). This implies that sickness partly accounts for the days lost from school by the pupils which eventually affect their academic performance.

Results in Table 11 shows that fever (34.0\%) was the main reason for missing school. One of the teachers also pointed out that at times pupils miss lessons due to sickness.

Findings in Figure 6 shows that nearly half of the children (45.4\%) fall once in three months. This means that the level of absenteeism is quite low. This was also supported by one of the school head teachers who pointed out that they do not have serious cases of children missing school most especially due to sickness, although he admitted that there are isolated cases.

\section{Strategies to address the specific health care needs of children for purposes of improving their academic performance.}

hows that the best way the school is using to help children who are sick is to give them medicine (100\%) while some are sent to hospital (77.3\%). In an interview with one of the school head teachers he pointed out that they normally treatment children at school through the use of the school nurse, but in case the sickness persist then they children are taken to the hospital for thorough treatment.

Findings in Table 19 shows that the respondents were mainly advised to keep the school compound clean (97.9\%) in order to avoid contracting diseases such as cholera and diarrhea. This was also supported by one of the head teacher who noted that they always advise children to keep the school compound clean and take care of their personal hygiene in order to avoid falling sick. Teachers who answered the questionnaires also noted that both girls and boys are always advised to observe personal hygiene.

Through Focus Group Discussion the parents gave the following suggestions for the improving of the health of children so as to improve their academic performance. Sensitization of parents about their children nutrition which boosts their immune system, providing safety nets/protective measures from harmful conditions like boots during rainy sea- 
sons, using mosquito nets at home among others. This can easily be conducted by medical personals both at the district and municipality levels.

NGOs should supplement on government efforts by filling the gaps left by the government policies for example providing water tanks to schools by "save the children", "UNICEF" etc. so as to improve on children's hygiene standardized. "Go back to school by picfare".

Pupils should be sensitized on preventive measures against contingent diseases, contraction diseases and how some diseases are caused so that they can be well equipped with knowledge about their surroundings.

The government should ensure provision of free drugs to the nearest health dispensaries and government hospitals and even in government schools for easy access drugs like Coartem deworming tablets, mosquito nets among others. Government should impose favorable health policies to gear health are activities in the municipality these policies should improve on the vaccination measures as the first priority to avoid the six killer diseases.

Parents proposed that there should be regular checkup both at home and at school, this can be through monitoring and observing children's behavior when they are playing or isolated from their friends one of the parents said "children do not learn from class only but also when they are playing e.g. in class the teacher can teach them to count from 12-5 but when they are playing they can score 10 goals and be able to know that from 5 the other digits are $6,7,8,9,10^{\prime \prime}$.

They also thought of empowering senior women teachers at school to fully sensitize pupils about their day to day life and how to prevent themselves from various obstacles in life that can endanger their health.

They concluded that the government has tried so much to eradicate and achieved a lot in reducing the six killer diseases and as of now malaria is on the track. Thus, viewing the country as developing immunization is seen to have improved since they (health personnels) no longer immunize the 6 killer diseases only, but also give discounting tablets and vitamins to ensure people health of the child.

\section{Discussion of results:}

Findings in Table 1 revealed that the majority of the respondents fell in the age group of 10-14 years
(92.8\%) and the smallest age group is 15-19 years. This is explained by the fact that the study respondents were primary five-pupils. Most of the pupils were boys who made up $52.6 \%$, compared to girls who were $47.4 \%$.These intents to the high dropout rates for girls as compared to boys in upper classes of primary schools. These results are close with a study by (Ahikire et al., 2019) which reported that only 51 girls out of 100 complete primary education as opposed to 56 out of 100 boys.

Results in Table 3 shows that $38.1 \%$ of the pupils were from primary five. This is followed by $28.6 \%$ in primary 7 and $28.9 \%$ for primary 6 . The facts show that the number of pupils was highest in primary five, were much willing to participate in the study.

the distribution of the respondents by religious affiliation was as follows; Catholic (29.9\%), Protestant (55.9\%), SDA (3.1\%) and Islam (11.3\%). It should be noted that this was simply a product of systematic random sampling.

Findings in Table 5 shows that the majority of the pupils' parents belonged to the business men/women (38.1\%) category as compared to other occupations. The smallest percentage of pupils had parents who are peasant farmers. This could possibly be attributed to the fact that the municipality is located in an urban setting.

Findings in Figure 1 shows that nearly half of the children (49.5\%) fall sick at least once a year. Other findings with regard to how often children fall sick were as follows; $20.6 \%$, are reported to fall sick at once every two months, $15.5 \%$ monthly, $8.2 \%$ twice a week and $6.2 \%$ once a week. This implies that children fall sick less frequently as reflected in the declining percentages as the period shortens. The most common kind of sickness that children always suffer from is Cough and flu (57.7\%) a result slightly higher than 33\% reported by (Fendrick et al., 2003) . This is then followed by malaria (36.1\%), which is much severe and can affect their school academic performance because it would lead to absenteeism. These results agree with a study by (Mpimbaza et al., 2020) which reported a prevalence range of < $1 \%$ to $54 \%$ among admissions of children aged 1 month to 14 years in Uganda. Others diseases such as diarrhea, headache, etc ( $4.1 \%)$ and yellow fever (1.0\%). This means that children in Fort-Portal Municipality are more vulnerable to catching cough and flu. This can probably be attributed to the dusty nature of where children play. Through Focus Group Discussion with the parents it was also 
identified that cough and flu are the major illnesses that children suffer from.

Results in Table 6 illustrated that majority of the children (77.3\%) had friends who were always falling sick. This could be attributed to the fact that at an early age the immunity of children is still weak that makes them susceptible to contract communicable diseases such cough and flu.

Statistics in Table 7 shows that majority of the respondents (54.7\%) pointed out that their friends always suffer from cough and flu. This validates with earlier findings presented in Figure 2 which also showed that most common kind of sickness among pupils in Fort-Portal Municipality in Kabarole district is cough and flu.

hows the case of the outbreak of a particular disease encountered mixed responses from the pupils. Majority of the pupils (76.3\%) responded no. However, some responded yes (23.7). (14 children) noted that the major outbreak of a particular disease that had been experienced in their schools was cough flu. Meanwhile, others identified malaria and a limited number identified other diseases such as diarrhea (2 children).

SUMMARY, CONCLUSIONS AND RECOMMENDATIONS

\section{Summary}

The Study was composed of 114 respondents, namely; 97 were pupils and the remaining 17 were key informants. Majority of the respondents fell in the age group of 10-14 years (92.8\%) and the smallest age group is 15-19 years. Most of the pupils were boys who made up $52.6 \%$, compared to girls who were $47.4 \%$. Majority of the pupils (38.1\%) were from primary five. In terms of religion, most of the pupils were Protestants (55.9\%). Majority of the pupils' belonged business mean/women (38.1\%) compared other occupations.

The study investigated the common health problems that affect primary school performance in Fort-Portal Municipality, Kabarole district and they were as follows; Cough and flu (57.7\%). This is then followed by malaria (36.1\%), which is much severe and can affect their school academic performance because it would lead to absenteeism, others diseases such as diarrhea, headache, etc ( $4.1 \%)$ and yellow fever (1.0\%).

Attention was then shifted to how poor health affects children's academic performance in Fort portal Municipality Kabarole district. The study findings showed that the performance of majority of the pupils (59.8\%) had been affected by sickness. The effect included; absenteeism (36.1\%), lack of concentration in class (27.8\%), missing tests (23.7) and exams (22.7\%).

The study also handled gender disparities in health care provision among boys and girls of school going age and it was established that girls get preferential treatment when it comes to accessing medical acre from the school nurse.

Finally, the study investigated the strategies to address the specific health care needs of children for purposes of improving their academic performance. The study showed that provision of medicine was viewed as the best option and this was then followed by being attended to by the school nurse, taking children to hospital and giving special food among others.

\section{Conclusions}

The study concluded that cough and flu is the most common health problem faced by pupils in Fort Portal, Kabarole district, but which is less severe compared to other common health problems that are experienced in the municipality include; malaria, diarrhea, headache, and yellow fever.

Poor health affects children's academic performance in Fort portal Municipality Kabarole district. Thus, in order to improve the academic performance of pupils in Fort Portal Municipality, there is need to address the health care needs of the children.

Contrary to the prevailing thinking that boys get preferential treatment in accessing health care. It is girls who are always given preferential treatment at school, perhaps because most nurses happen to be females who may be freer to interact and serve girls more effectively compared to boys.

There is no single way of improving the academic performance of pupils through tackling their health care needs. However, provision of medicine to the children remain the most important option as well as preventive measures such as general cleanliness, personal hygiene and sleeping under mosquito nets.

\section{Recommendations}

Basing on the study findings it was established that cough and flu is the most common health problem 
that is affecting the performance of pupils in Fort Portal municipality. Therefore, the school together with other stake holders such as the government, NGOs, Parents and individuals should join hands in sensitizing the children about the spread of cough and flu so that it can be prevented.

It is also important to note that efforts should be directed by government through the Ministry of Education and Sports towards enhancing health education in schools. In fact the teacher training curriculum should include training on basic health care so that teachers are properly equipped to address the health care needs of the pupils.

It's also recommended that the government through the Ministry of Education and Sports in collaboration with schools and other stake holders should direct its efforts towards the recruitment of nurses that would be resident in the school and held responsible for treating the children while being paid by the government as a school health worker.

The government through the Ministry of Microfinance should also ensure that efforts are put towards the establishment of income generating projects in order to raise the level of income of the people so that parents can be able to treat their children. It is also important for parents to be empowered economically so that they can purchase mosquito nets to be used at their homes by both adults and children.

The government should ensure that more NGOs are encouraged to extend their operation to Fort portal Municipality since addressing the health care needs of children can not be handled by the parents and school only, but it requires a concerted effort. The influx of more NGOs will help in reducing the scope of the task to be performed by the few NGOs in addressing the health care needs of the orphans.

The government through the Ministry of Health should work towards the provision free health services to school going children. There is also need for the children to under go regular medical check up preferably once every three weeks so that health problems which are affecting the academic performance of children can be minimized.

\section{Acknowledgement}

To my supervisor Mr. Ssengendo John who has provided inspiration for and evaluation of this material.

To Mr. Opio Douglas who helped me during the study. May God bless him abundantly.

\section{Limitations of the study}

The limitation of the study was inadequate funds and constrain of time. This explains why only one district was used to represent Uganda and only the Municipality was used to represent the entire district.

Incorrect answers, which were filled in questionnaires, were also another limitation. The researcher had to ensure that the questionnaires were filled by the pupils under supervision to avoid recurrence of such mistakes.

Most schools were busy and as such, it was not easy to make an appointment with the school authorities for data collection to take place. This is was solved by going to the schools at least two weeks before data collection so that appointments can be made. 
Table 20.

1) Behrman R.J and Laury V. (1994). Children's health and achievement in school, the World Bank, Washington DC,USA.

2) Todaro, P. M and Smith, J.C. (2003). Economic development, 8th edition, Pearson education limited, Edinburgh.

3) UNICEF (2005). The State of the world's Children: Childhood under threat, UNICEF publication's house, New York.

4) Bellamy. C UNICEF. (1999) The State of the World's Children 1999. UNICEF, 131 pages. https://books.googl e.co.ug/books?id=eAdkfVleP-QC\&redir_esc=y

5) Josephine A., \& Aramanzan M. (2019) A Survey On Re-Entry Of Pregnant Girls In Primary And Secondary Schools In

Uganda. https://www.education.go.ug/wp-content/uploads/2019/07/gender_Report-on-Girls-Re-ntry-in-s chool.pdf

6) Fendrick AM, Monto AS, Nightengale B, et al. The economic burden of non-influenza-related viral respiratory tract infection in the United States. Arch Intern Med 2003;163:487-94 [PubMed] [Google Scholar ]https://doi.org/10.1001/archinte.163.4.487PMid:12588210

7) Mpimbaza, A., Walemwa, R., Kapisi, J. et al. The age-specific incidence of hospitalized paediatric malaria in Uganda. BMC Infect Dis 20, 503 (2020). https://doi.org/10.1186/s12879-020-05215-zhttps://doi.org/10.1186/ s12879-020-05215-zPMid:32660434 PMCid:PMC7359223

8) Republic of Uganda Ministry of Health (April 2003). Annual sector strategic plan 2000/2001-2004/2005, mid term review, Kampala, Uganda. 